Original Research Article

\title{
Role of Pharmacology in self medication practices among undergraduate medical students in a medical college and hospital in North India
}

\author{
Sanchali Jindal ${ }^{1}$, Preeti Garg ${ }^{2 *}$
}

${ }^{1}$ Intern, GMC, Patiala, Punjab, India

${ }^{2}$ Department of Pharmacology, Adesh Medical College and Hospital, Shahabad, Haryana India

Received: 15 March 2019

Accepted: 18 March 2019

\section{*Correspondence to:}

Dr. Preeti Garg,

Email: preetigarg@gmail.com

Copyright: (C) the author(s), publisher and licensee Medip Academy. This is an openaccess article distributed under the terms of the Creative Commons Attribution NonCommercial License, which permits unrestricted noncommercial use, distribution, and reproduction in any medium, provided the original work is properly cited.

\begin{abstract}
Background: Self medication is an important component of primary health care. It involves treatment of common ailments on ones own initiative or on the advice of a pharmacist. With the easy accessibility to information regarding use of drugs, there is an alarming increase in the self medication practices. Medical students, during their course of study gain considerable knowledge of drugs and it may have an influence on their self medication practices. The present study was designed to gather the knowledge, attitude and behavior of medical students towards self medication and whether an increased knowledge of drugs further promoted self medication.

Methods: A questionnaire based study was carried out on students of $2^{\text {nd }}$ semester students relating to their knowledge, attitude and practice of self medication.

Results: Though the knowledge regarding drugs is quite comparable in both the first and third year medical students, 39\% students in group A took the medicine without doctors' advice in the last month whereas $58 \% 5^{\text {th }}$ semester students in group B did the same.

Conclusions: The frequency of self medication is higher among third year students as they believe that the medical training makes them capable enough to self medicate easily without any harm. Hence, there is need to promote rational self medication practice to bring awareness about irresponsible self medication.
\end{abstract}

Keywords: Attitude, Awareness, Knowledge, Practice, Rational, Self medication

\section{INTRODUCTION}

Self medication is an integral part of self care and involves treatment of common health problems without consulting a medical practitioner. WHO mentions that selfmedication involves the use of medicinal products by the consumer to treat self-recognized disorders or symptoms or the intermittent or continued use of a medication which was prescribed by a physician for a chronic or recurring disease or symptoms. ${ }^{1}$ The 'non-prescription' or 'over the counter' drugs (OTC) are commonly used in self medication. ${ }^{2}$ Self-medication is a serious global issue as the irrational use of drugs is on the rise these days. A number of factors that promote drugs intake by general population, students, and potential risks associated with such practices have come into light. Most commonly used drugs are NSAIDS like ibuprofen and antipyretics like paracetamol..$^{3,4}$

There could be various reasons underlying this increasing trend like illness is too trivial for consultation (common cold, fever, headache), lack of time to see a doctor, high treatment costs, previous experience with the use of drug, easy availability of these OTC drugs, lax regulatory 
authorities etc. In today's tech savvy era, Internet comes in handy to get information regarding use of drugs for common day to day ailments. Inappropriate use of these drugs can bring about a brief symptomatic relief but in the long term, may hinder the correct diagnosis, undermine the contraindications and warnings of drug use, leading to development of resistance as seen with antibiotics, or many adverse effects. ${ }^{2,3,5}$ In a study conducted by Verma ,antibiotic resistance was found to be the biggest hurdle in fighting bacterial infections and self medication was the major factor behind this. ${ }^{2}$

On the contrary responsible self medication can help to prevent and cure common illnesses that don't require medical consultation without much constraint on time and ones pocket. But responsible SM is possible only with appropriate health information.

Self-medication is more likely among medical students as they have easy access to drug information sources, and their knowledge to self-diagnose and self-medicate increases as they progress through the course. In the first professional year, they have gathered their knowledge of drugs from family members or peers, earlier experience with the use of drugs or advertisements on television or internet. All this information leads to confidence to self medicate. While pursuing their course, they attain vast knowledge varying from pathophysiology of diseases to therapeutics (about mechanism of action, dose, route of administration, adverse effects, interactions with other drugs and food etc.) of drugs in pharmacology in second professional (here, $5^{\text {th }}$ semester students). ${ }^{6,7}$

Thus, it has become crucial to know the prevalence, attitude and practice of the medical students towards self medication due to their knowledge in the same field. This will give an insight about the correct adaptation of knowledge acquired and its clinical application. The practice of self medication if done in an appropriate way can save medical resources, cost and time wasted on minor conditions. 8Medical students by rational self-medication could promote awareness in their patients and the general public for responsible self-medication. ${ }^{9}$

The objective of this study was to gather information regarding self medication practices in undergraduate medical students. And to comparatively evaluate whether the knowledge about drugs and diseases brings about any change in these practices

\section{METHODS}

This study was an ICMR-STS project conducted at Gian Sagar Medical College and Hospital. A descriptive crosssectional survey was carried out among $2^{\text {nd }}$ and $5^{\text {th }}$ semester MBBS students. 90 students from each of the above two semesters were enrolled in the study. A questionnaire was designed to access the knowledge, attitude and behaviour of the medical students towards self medication and was validated. The students who were involved in the validation of the questionnaire were not included in the final analysis.

Informed consent was taken from the students and they were told that their participation in this study is anonymous, voluntary and they can withdraw from the study at any time. The questionnaire consisted of 4 sections where the first section dealt with demographic profile of the respondent. Second section consisted of 5 questions to gather the knowledge of respondent about the drugs. Third section consisted of 5 questions to know the reasons behind this practice of self medication. Final section was about the behavior related to drug usage.

\section{The students were divided into 2 groups}

- Group A - 90 students of $1^{\text {st }}$ year ( $2^{\text {nd }}$ semester $)$

- Group B - 90 students of $3^{\text {rd }}$ year $\left(5^{\text {th }}\right.$ semester $)$

Through the Google Forms tool, the questionnaire was converted in an online link form and this link was forwarded in What's App group of the students. Along with the link, appropriate guidelines regarding how to fill the form where duly mentioned. Students were given a time of one day and the data was collected in the form of an excel response sheet. History of self medication in preceding one year from the day of study was noted.

\section{Statistical analysis}

All statistical calculations were done using computer program Microsoft Excel Version 10. The results were analysed as percentages.

\section{RESULTS}

The questionnaire was distributed to hundred students of group A and group B each. 90 students of group A and 89 students of group B completed the questionnaire.

Table 1: Demographic profile of the students.

\begin{tabular}{|lll|}
\hline Group & A (Total=90) & B (Total= 89) \\
\hline Mean age & $19.05 \mathrm{yrs}$ & $21.02 \mathrm{yrs}$ \\
\hline Sex & $\mathrm{M}=40, \mathrm{~F}=50$ & $\mathrm{M}=42, \mathrm{~F}=47$ \\
\hline $\begin{array}{l}\text { Is any of your } \\
\text { parent a doctor? }\end{array}$ & $\mathrm{Yes}=14$ & Yes $=11$ \\
\cline { 2 - 3 } & $\mathrm{No}=76$ & $\mathrm{No}=78$ \\
\hline
\end{tabular}

When assessing the knowledge of drugs in both the groups there was not much difference between the information about dosage, side effects and route of administration of drugs. But group A had inadequate knowledge about the completion of course of antibiotics. $63 \%$ of group A students correctly identified the sequence of how a drug is metabolized in the body as compared to $74 \%$ in group B. $94 \%$ students of group A and $97 \%$ students in group B believed that all medicines like vitamins, paracetamol, cough syrups and antibiotics have side effects when taken in excess. On self medication, in Group A only a few 
respondents complained of sedation. On the other hand, the major side effects experienced by group B were sedation, nausea, gastrointestinal disturbances like acidity, diarrhea, gastritis and vomiting.

The most common reasons for self medication in both the groups were self-confidence regarding awareness about the medication and prior experience of illness (Figure 1).

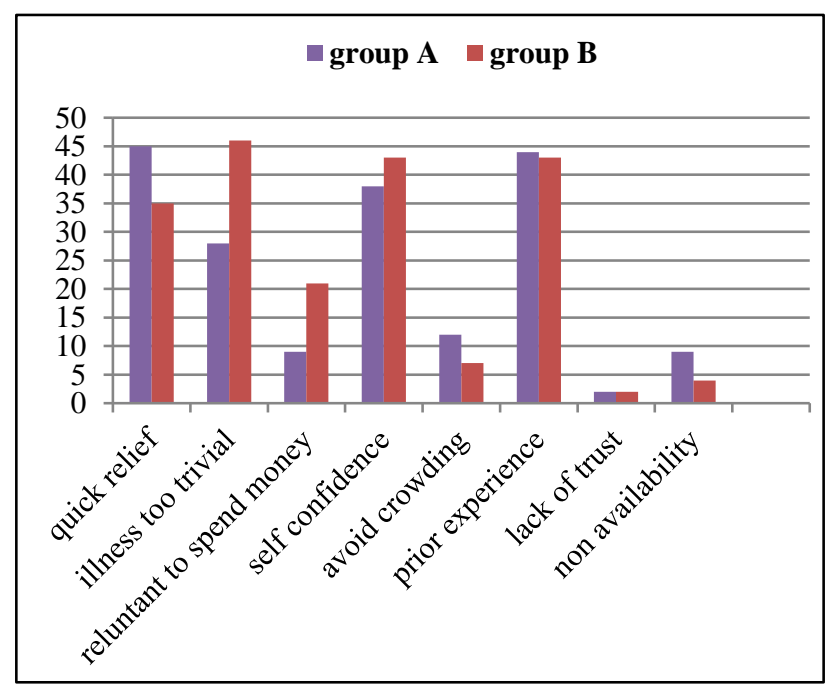

Figure 1: Reasons for self medication.

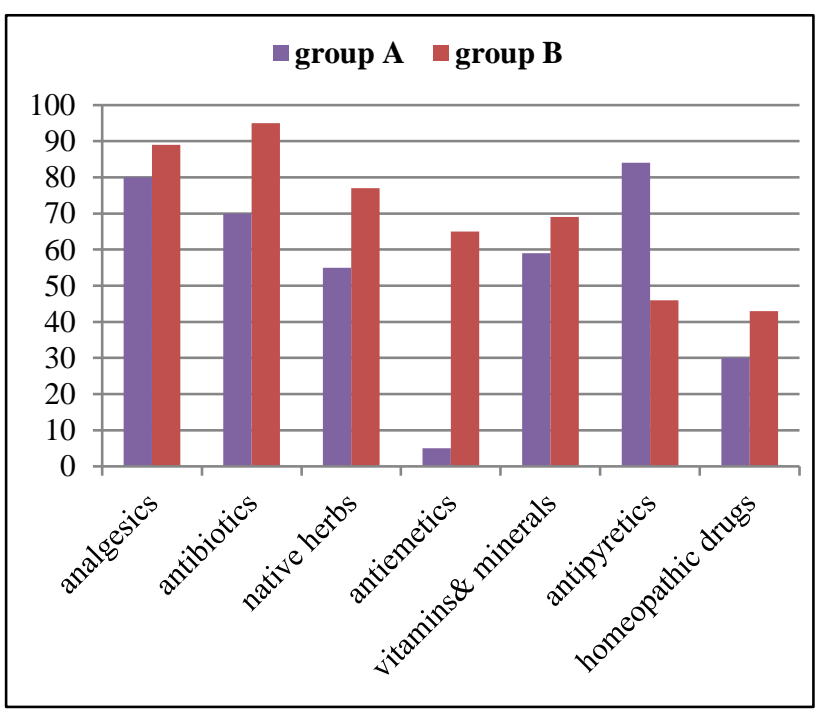

Figure 2: Sources of information of self medicated drugs.

The most common sources of information of self medication drugs was advice from pharmacist and old prescriptions in group A and textbooks in group B (about $59 \%$ in each group) as shown in Figure 2.

Among the type of drug administered antibiotics, antiemetics, native herbs and vitamins and minerals are used extensively by group B as compared to group A Antipyretics on the other hand were used more by group $\mathrm{A}$ $(80 \%)$ in contrast to group B $(23 \%)$ as shown in Figure 3.
The most common ailments for which self-medication is done are fever, headache followed by cough, common cold and sore throat in both group A and B as given in Figure 4.

Self medication is acceptable to medical students was agreed upon by $33.19 \%$ of students in group B as compared to only $6.5 \%$ in group A.

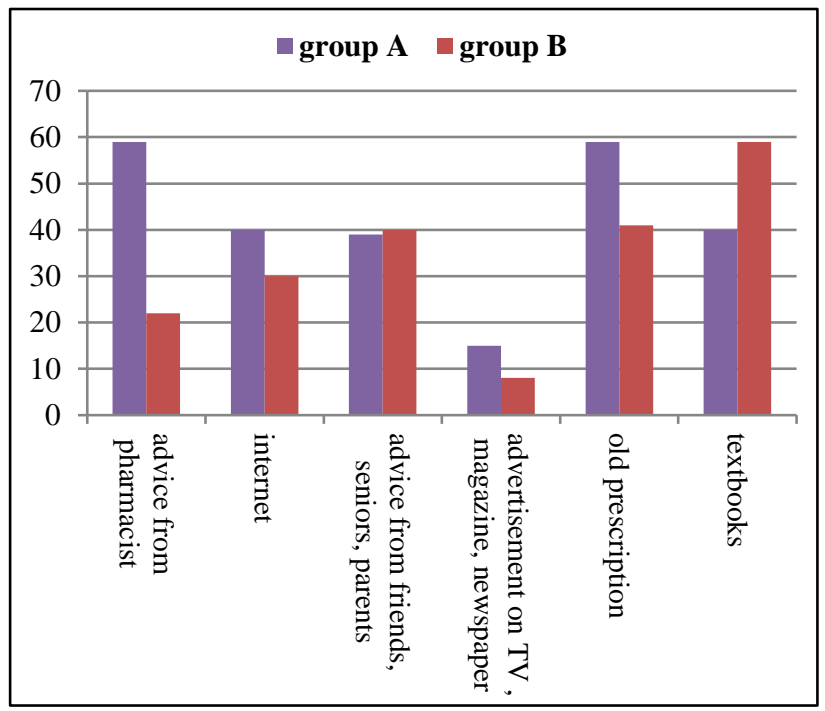

Figure 3: Various drugs that are commonly self medicated.

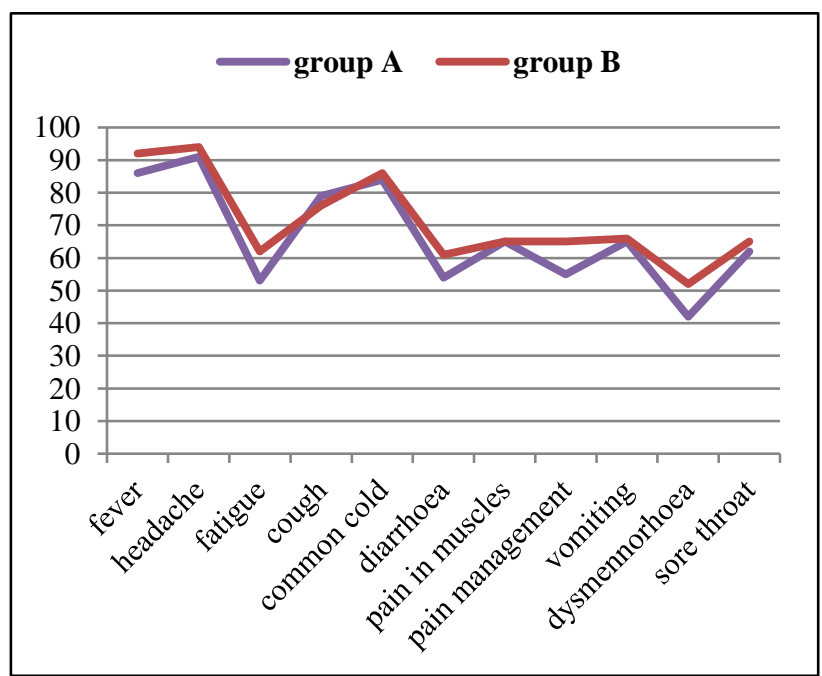

Figure 4: Various symptoms for which drugs are self medicated.

Self medication is harmful if taken without proper knowledge of drugs was opined by $88 \%$ and $85 \%$ of students in group A and group B respectively. 39\% students in group A took the medicine without doctors' advice in the last month whereas $58 \%$ students in group B did the same. $65 \%$ students from (group B) opined that knowledge of pharmacology has not only enhanced their skills but has also led to an increase in frequency of self medication. 


\section{DISCUSSION}

In both the Groups A and B, the most common reason for self medication was prior experience of illness which is similar to findings reported by Gutema et al. ${ }^{6}$ Mild nature of disease was quoted as another common reason.The drugs commonly self medicated are antipyretics, analgesics besides antibiotics, native herbs, vitamins and minerals. Symptoms for which drugs are usually administered are mainly fever, headache, cough, cold, sore throat, and pain. Similar findings have been reported by Kasulkar et al, Shankar et al, and Banerjee et al, in studies conducted by them. ${ }^{3,5,10}$ Acidity and dysmennorhoea as common symptoms apart from the above mentioned have also been reported. ${ }^{6}$

The sources of information about the drugs were mainly through pharmacists and old prescriptions in the first year students, and textbooks including pharmacopeias' or pharmacology journals in the third year students. Gutema et al, and Abay et al, in studies conducted by them reported that Pharmacists play a key role in providing information to the consumers about the proper use and adverse effects of medicines. ${ }^{6,11}$

Regarding whether knowledge of drugs (Pharmacology) has any influence on self medication practices of undergraduate medical students, it was found that the practice of self medication is present in both the groups, but it is higher in group B students. These results are quite expected due to higher knowledge of group B students in pharmacology. $2^{\text {nd }}$ semester students are not exposed to the knowledge of drugs or diseases while at the end of 5th semester, Pharmacology syllabus is complete as per the Indian medical curriculum.

Kasulkar et al, in his study documented that the prevalence of self medication varied amongst different years of medical students and increased from first year to final year owing to the knowledge acquired about drugs which is comparable with the findings of previously conducted studies. ${ }^{3,9,11}$

The presence of medical subjects in faculties' curricula affects the attitude of students towards the safety of drugs. This has been shown by Klemenc- Ketis Z et al, in their study, according to which the prevalence of self medication was more in medical students in senior years. ${ }^{12}$ Majority of the students agreed that medical knowledge is necessary for administration of medicine by self.

In present study, use of antibiotics, native herbs and antiemetics were significantly high amongst third year students. Sontakke et al, also reported a higher use of antibiotics by third year students. ${ }^{13}$ Also, it was reported that the prevalence of self medication is comparable in both the groups. Even though senior medical students have a better knowledge about certain aspects of self-medication owing to medical training. But even the junior students who have not been taught academically about use of drugs are well aware about most of these which may be due to easy access to information. ${ }^{13}$

In a study conducted by Gyawali et al, it was found that semester of study, gender, age, and profession of the parents had little effect on the prevalence of selfmedication among basic science medical students. ${ }^{8}$ A study done on first year medical students revealed that due to fear of adverse drug reactions, risk of making a wrong diagnosis or consuming a wrong drug, the first year students refrained from self medication. ${ }^{14}$

Self medication is a double edged sword. If practiced responsibly, it can improve health status of the community and aid in cost effective treatment of common ailments. If not, the danger of interactions and adverse effects could increase. Hence proper awareness and education regarding self-medication, stringent regulations regarding pharmaceutical advertising and availability are the need of hour.

Medical students are going to be future doctors and will carry this practice forward. So an awareness through new modules, seminars and continuing medical education should be spread about the wise and responsible use of self medication.

\section{ACKNOWLEDGEMENTS}

Authors are highly thankful to the entire faculty and supporting staff of the Department of Pharmacology for their support. Authors are also grateful to the participating students of first and second Professional MBBS, for their co-operation and active interest in the conduct of the study.

Funding: No funding sources

Conflict of interest: None declared

Ethical approval: The study was approved by the Institutional Ethics Committee

\section{REFERENCES}

1. World Health Organization. Guidelines for the regulatory assessment of medicinal products for use in self-medication. 2000. Available at: http://apps.who.int/ medicinedocs/pdf/s2218e/s2218e.pdf. Accessed 14 July 2016.

2. Verma RK, Mohan L, Pandey M. Evaluation of self medication among professional students in North India: Proper statutory drug control must be implemented. Evaluation. 2010 Jan;3(1):60-4.

3. Kasulkar AA, Gupta M. Self medication practices among medical students of a private institute. Indian $\mathbf{J}$ Pharmaceut Sci. 2015 Mar;77(2):178.

4. Zafar SN, Syed R, Waqar S, Zubairi AJ, Vaqar T, Shaikh M, et al. Self-medication amongst university students of Karachi: prevalence, knowledge and attitudes. J Pak Med Assoc. 2008 Apr;58(4):214-7. 
5. Shankar PR, Dubey AK, Dwivedi NR, Nandy A, Barton B. Knowledge, perception and practice of selfmedication among premedical and basic science undergraduate medical students. Asian J Med Sci. 2016 Oct 31;7(6):63-8.

6. Gutema GB, Gadisa DA, Kidanemariam Z, Berhe D F, Berhe AH, Hadera M G, et al. Self-Medication Practices among Health Sciences Students: The Case of Mekelle University. J of Appl Pharmaceutical Sci. 2011;1(10):183-9.

7. Bennadi D. Self-medication: A current challenge. J Basic Clin Pharma. 2013 Dec;5(1):19.

8. Gyawali S, Shankar RP, Poudel PP, Saha A, Knowledge, Attitude and Practice of Self-Medication Among Basic Science Undergraduate Medical Students in a Medical School in Western Nepal. J Clin Diagn Res. 2015 Dec; 9(12):FC17-22.

9. Kumar R, Goyal A, Padhy BM, Gupta YK. Selfmedication practice and factors influencing it among medical and paramedical students in India: A twoperiod comparative cross-sectional study. J Natural Sci Biol Med. 2016 Jul;7(2):143-8.

10. Banerjee I, Bhadury T. Self-medication practice among undergraduate medical students in a tertiary care medical college, West Bengal. J Postgrad Med. 2012;58(2):127-31.
11. Abay SM, Amelo W. Assessment of Self-medication practices among medical, pharmacy, health science students in Gondar University, Ethiopia. J Young Pharmacists. 2010 Jul 1;2(3):306-10.

12. Klemenc-Ketis Z, Hladnik Z, Kersnik J. Selfmedication among healthcare and non-healthcare students at University of Ljubljana, Slovenia. Med Principles Pract. 2010;19(5):395-401.

13. Sontakke SD, Bajait CS, Pimpalkhute SA, Jaiswal KM, Jaiswal SR. Comparative study of evaluation of self-medication practices in first and third year medical students. Int J Biol Med Res. 2011 Apr 30;2(2):561-4.

14. James H, Handu SS, Al Khaja KA, Otoom S, Sequeira RP. Evaluation of the knowledge, attitude and practice of self-medication among first-year medical students. Med Principles Pract. 2006;15(4):270-5.

Cite this article as: Jindal S, Garg P. Role of Pharmacology in self medication practices among undergraduate medical students in a medical college and hospital in North India. Int J Basic Clin Pharmacol 2019;8:657-61. 